\title{
Reseña de Algunos Regímenes Aduaneros Especiales Usados como Estímulo a las Exportaciones
}

\author{
Jorge I. Arce Rodriguez \\ Ex Director General de Aduanas
}

\section{PUERTO O ZONA FRANCA.-}

Definición. Según el Convenio del Consejo de Cooperación Aduanera sobre "Simplificación y Armonización de los Procedimientos Aduaneros firmado en Kyoto (1973), es:

"Una parte del territorio de un Estado en la que las mercancías que en ella se introduzcan se consideran generalmente como si no estuviesen en el territorio aduanero con respecto a los derechos e impuestos de importación y no están sometidas al control habitual de la aduana".

Se puede distinguir entre zonas francas industriales y zonas francas comerciales.

"Zonas Francas comerciales, son zonas en las que las mercancías se admiten en espera de su destino posterior, estando normalente prohibido elaborarlas o transformarlas".

"Zonas francas industriales, son zonas en las que se admiten mercancias a las que se les puede someter a las operaciones de perfeccionamiento que se hayan autorizado".

En consecuencia, son pues, un puerto o una parte de un puerto, o aún un simple lugar, cuyos límites son vigilados por la Aduana y que están situados 0 , bajo ciertos aspectos, considerados como situados en el exterior de la frontera Aduanera, en las cuales las mercancías generalmente son admitidas con exención de derechos e impuestos a la importación y no están normalmente sometidas al control aduanero. Las mercancías, allí, pueden ser depositadas, almacenadas, acondicionadas y expuestas sin ninguna restricción o, bajo ciertas condiciones, ser trasbordadas, puestas a la venta, transformadas o terminadas.

NOTA.- Estas definiciones no se aplican a los aeropuertos fran$\cos$

En el Código Aduanero Uniforme Centro Americano (CAUCA) No hay definición; sin embargo, son varios los países miembros del Mercado Común Centro Americano, que tienen en funcionamiento Zonas Francas comerciales e industriales, creadas mediante legislaciones propias.

En los países de la ASOCIACION LATINO AMERICANO DE INTEGRACION (ALADI), se está adoptando la definición de Kyoto sobre este particular.

En EUROPA, se consideraban más bien, como núcleos interna- cionales de distribución de mercancías, ubicados en la periferia delcontinente europeo, como por ejemplo: los puertos francos como el de HAMBURGO, constituyen centros eficaces para encausar y facilitar el comercio entre los países del centro y del este europeo, con el resto del mundo, sea para importar como para exportar, es decir, pues, que eran núcleos de distribución y de tránsito comerciales. Desde ese punto de vista allí cumplieron eficazmente sus funciones.

Actualmente, la creación de puertos o zonas francas, obedece más bien a razones económicas, ligadas fundamentalmente con la necesidad o conveniencia de promover el desarrollo de una determinada zona del territorio nacional; promover o facilitaruna corriente comercial desde el extranjero y con destino a los países vecinos, generalmente meditarráneos; estimular la creación de complejos industriales o de determinadas industrias y aún, desarrollar industrias manufactureras a base de materias primas extranjeras y cuyo objetivo principal es la exportación (ventajas 
comparativas?) poder energético barato? materia prima?, mano de obra especializada y barata? antes de tomar decisiones habría que ANALIZAR.

En el hecho de pretender extender a zonas o porciones amplias del territorio nacional (Caso de Chile o del Brasil por ejemplo), las características del puerto o zona franca con sus sistemas de exoneraciones arancelarias sobregrandescantidadesde mercancías, en la práctica, tiende, por la alteración substancial de las características jurídicas de tal puerto franco en áreas de control aduanero, a crear una figura jurídica nueva que podría catalogarse como "zona sometida a regímenes arancelarios especiales".

Las modalidades que revisten en la actualidad los llamados "puertos o zonas francas", son bastante variadas y es interesante observar que muchas de ellas se apartan bastante del concepto clásico.

Son grandes las dificultades que se crean, en consecuencia, para el control aduanero, su relativa eficacia para el cumplimiento de los objetivos previstos en las normas respectivas, las dificultades y problemas que originan en el equilibrio de la balanza de pagos, y aún los efectos nocivos que crean en la opinión pública, en razón de los privilegios de orden tributario, que son la base de este régimen, asi como las enormes posibilidades de infracciones aduaneras de toda naturaleza que ellos entrañan, handeterminado por restarle sus características originales, en cuanto al de su territorio extraaduanero, y; en la actualidad, es difícil encontrar la aplicación de este régimen en su forma más pura y por el contrario, aparece desdibujado en el conjunto de las legislaciones nacionales, como un régimen de franquicias o de exoneración o rebaja de derechos, en razón del territorio. Aún más, se advierte en ciertos países europeos, Francia, por ejemplo, una opinión contraria a su establecimiento o mantención procurándose en cambio, su remplazo por el régimen de "Entrepot Industriel" (Depósito Industrial), que es una forma de régimen de almacenaje particular de materias primas, como se verá más adelante.

En América Latina, entre los países miembros de ALADI ex ALALC, tenemos por ejemploalgunas Zonas Francas Comerciales y Zonas Francas Industriales, unas que funcionan mixtas otras separadas.

ARGENTINA: En la Tierra del Fuego, Antártida e Islas del Atlántico Sur.

BOLIVIA: Cobija (Zona Franca Comercial) y otra Zona Franca Industrial; Zona Franca de funcionamiento mixto en el puerto peruano de llo.

BRASIL: Manaos (Zona Franca mixta).

COLOMBIA: Zonas Francas Comerciales y Zonas Francas Industriales separadas, en San Andrés, Barranquilla, Calí en

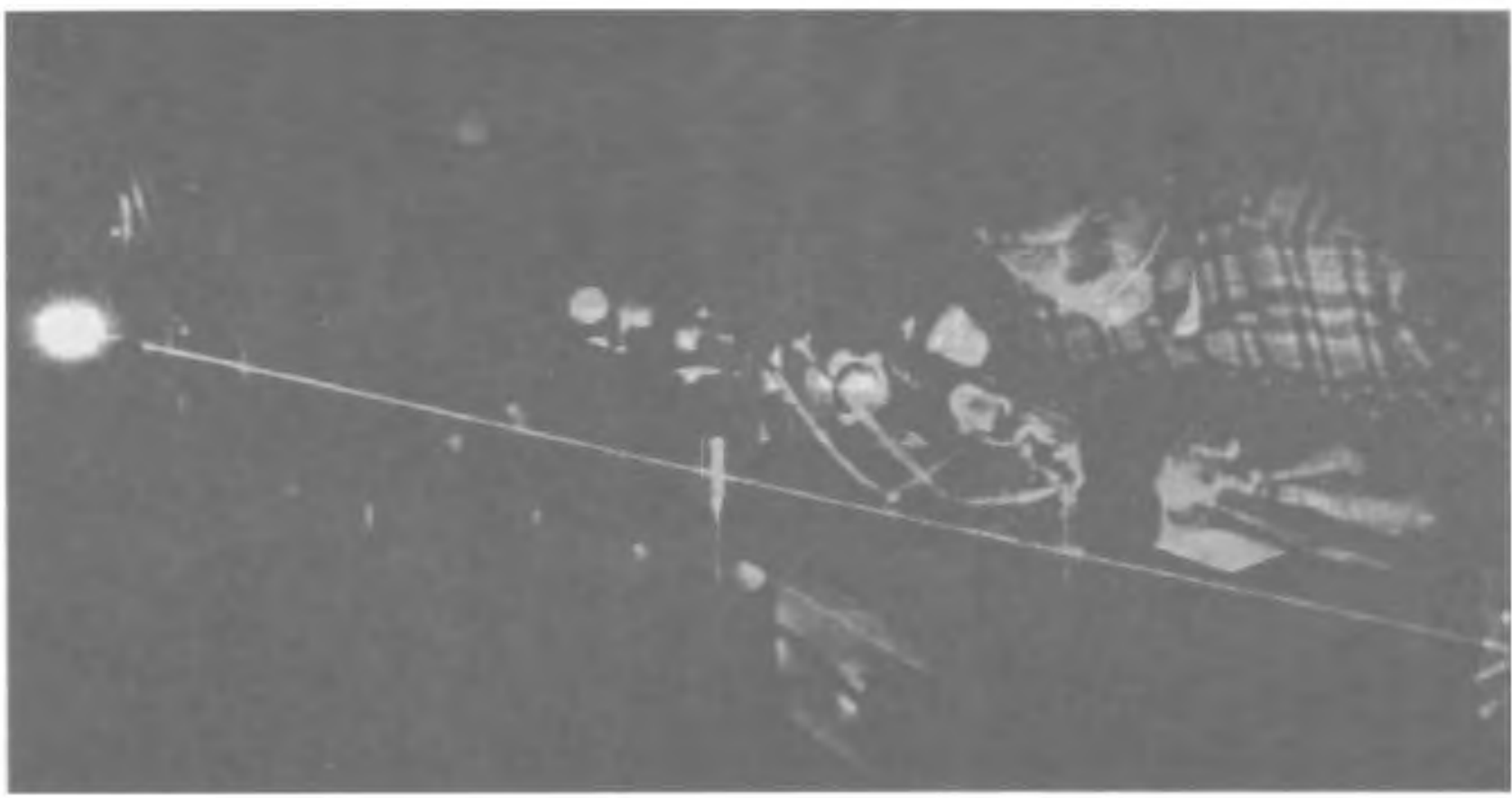




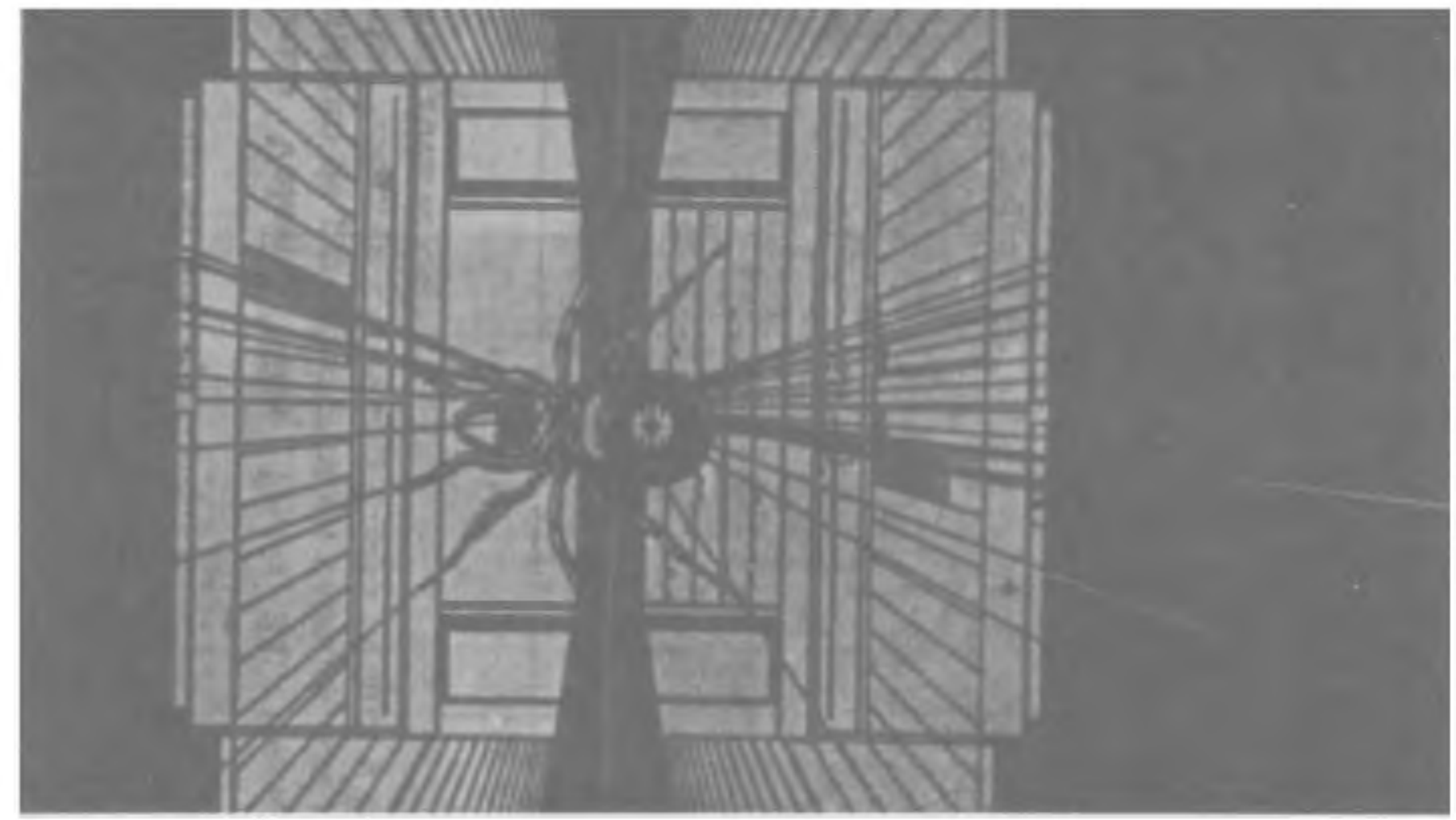

Cúcuta, en los puertos y zonas fronterizas.

CHILE: Iquique (Zona Franca mixta).

MEXICO: Baja California, el extremo noreste del Estado de Sonora.

PARAGUAY: En Santos y en Paranaguá (Brasil); en Puerto Zarate (en Argentina) y Nueva Palmira (en Uruguay).

PERU: En Tacna, llo, (en implementación) y creados en otros sitios peroque no están funcionando.

URUGUAY: Nueva Palmira y Colonia.

VENEZUELA: Zona Franca Comercial en la Isla Margarita, Estado de Nueva Esparta (1967), Zona Franca Industrial en Paranaguá en el Estado de Falcón.

Como se anota, en Europa, por los motivos expuestos, han dado buenos resultados y llenado su misión, más los puertos francos que las zonas francas o libres ubicadas en otros sitios, mayormente como facilidad para bajar costos operacionales portuarios y de distribución.

\section{PUERTOS FRANCOS EN} LOS PAISES EN DESARROLLO

Cuando el volúmen del comercio exterior es grande y existen motivos fundados para creer que un Puerto Franco no solo es útil, sino también necesario; y cuando hay otros factores, tales como de ubicación conveniente, vida barata, habilidades mecánicas y desempleo, la inversión y el costo de funcionamiento de un puerto de esta clase, puede estar justificado.

Existen muchos puertos así en los paises industrializados y unos cuantos en los países más jóvenes; sin embargo, NO siempre han conseguido los beneficios previstos por los partidarios de
Zonas Francas. En algunos casos, tales beneficios no han justificado las inversiones y los gastos de explotación.

No obstante, si después de realizar un estudio cuidadoso de todos los factores, el Gobierno de un país en desarrollo o menos industrializado, cree que los intereses de la nación se beneficiarán con el establecimiento del régimen de PUERTO O ZONA FRANCA, la adopción de los métodos holandeses probablemente resultarian menos costosos y al mismo tiempo más apropiado para lograr los resultados deseados (Vgr. Rotterdam). Estas zonas francas podrían ser útiles especialmente cuando los puertos de un país pueden utilizarse como lugares de transbordo para los productos de sus vecinos que no tengan salida al mar.

En tales circunstancias un 
PUERTO O ZONA FRANCA INDUSTRIAL resultaría beneficioso al:

A) Ofrecer oportunidades de empleo y desarollar conocimientos nuevos (tecnología).

B) Reducir los costos globales de las importaciones, al introducir productos semi-elaborados y materias primas, para su elaboración y terminación en el país.

C) Permitir la entrada de tales productos semi-acabados o materias primas y la exportación de los artículos terminados (productos compensadores), sin pagar derechos de aduana, especialmente a los países situados en el interior del continente y que no dispongan de acceso al mar. Lo cual ayudaría a desarrollar el sistema de transporte al interior. Además, la baratura de la mano de obra mejoraría la posición competitiva de tales productos en los nuevos mercados en desarrollo, lo que supone serán más importantes en el futuro.

Sin embargo, es bueno aclarar que los productos terminados en las llamadas Zonas Francas, carecen de trato beneficioso en las "Zonas de LibreComercio y Uniones Aduaneras", ya que se les considera como procedentes de terceros países.

\section{II.- ADMISION TEMPO-} RAL PARA PERFECCIONAMIENTO ACTIVO

Según lo define el Convenio de Kyoto, se entiende por tal:

"El régimen aduanero que permite recibir dentro del territorio aduanero, en suspensión de derechos e impuestos de importación, ciertas mercancías destinadas a ser exportadas, en un período de tiempo determinado, después de haber sufrido una transformación, una elaboración ouna reparación" (denominados "productos compensadores").

El fin principal de este régimen aduanero, es el de permitira las empresas nacionales ofrecer sus productos o sus servicios en los mercados extranjeros, a precios competitivos y contribuir así a asegurar mejores posibilidades de empleo a la mano de obra nacional. Sin embargo, esta concesión puede estar subordinada a la combinación de que las operaciones consideradas sean beneficiosas para la conomía del país y que no atenten contra los intereses de los productos nacio- nales de mercancías idénticas o similares a aquellas para las cuales el beneficio de este régimen ha sido solicitado.

Implica mayormente la suspensión total de los derechos e impuestos a la importación, sin embargo, pueden gravarse los desperdicios procedentes de la elaboración o de la transformación de las mercancías admitidas temporalmente para perfecccionamiento activo.

En las legislaciones nacionales, mayormente se exige que las mercancías exportadas provengan de mercancías importadas, sin embargo a veces se autoriza emplear mercancías equivalentes a aquellas mercancías que se consumen en el curso de la producción de los productos compensatorios exportados, sin estar efectivamentecontenidas en estas últimas (tales como los aceleradores, catalizadores, relentizadores).

La aplicación de este régimen mayormente está sometido a la constitución de una GARANTIA y puede estar acompañado de ciertas medidas especiales de

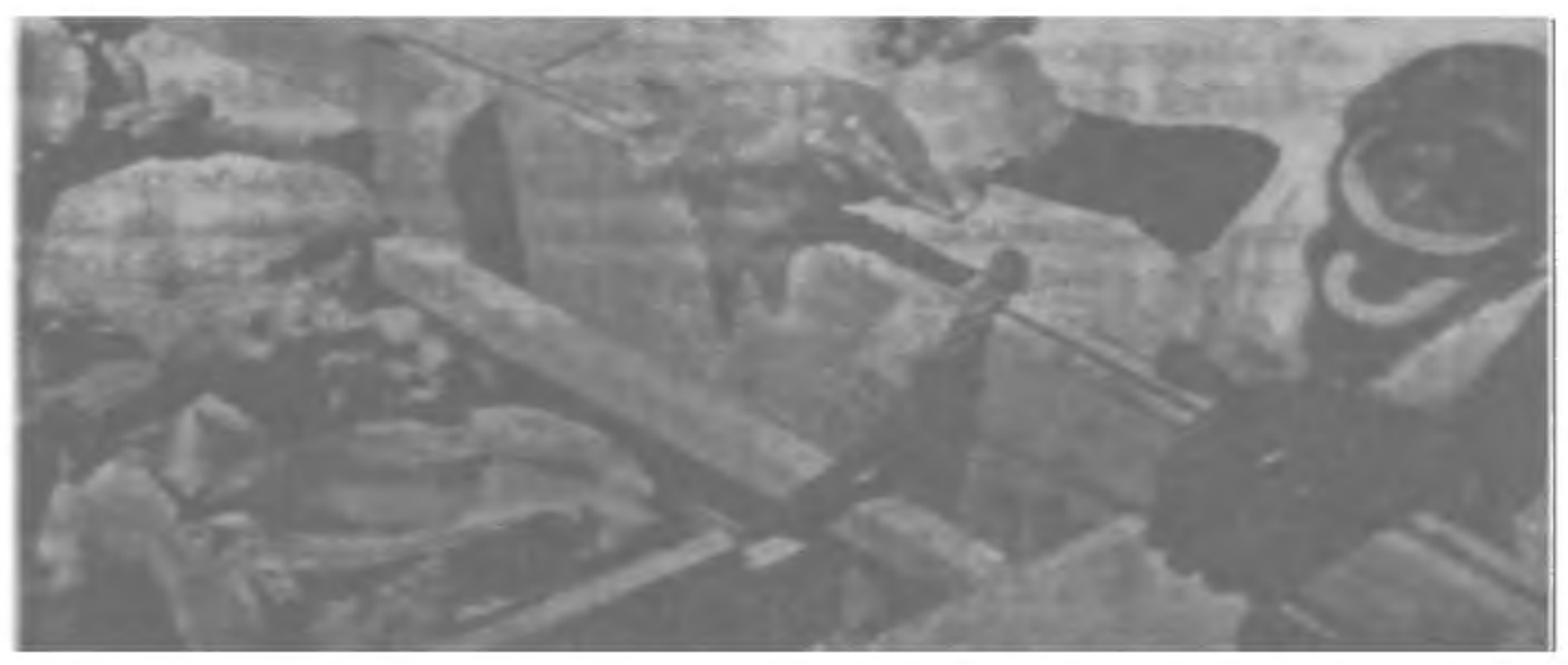




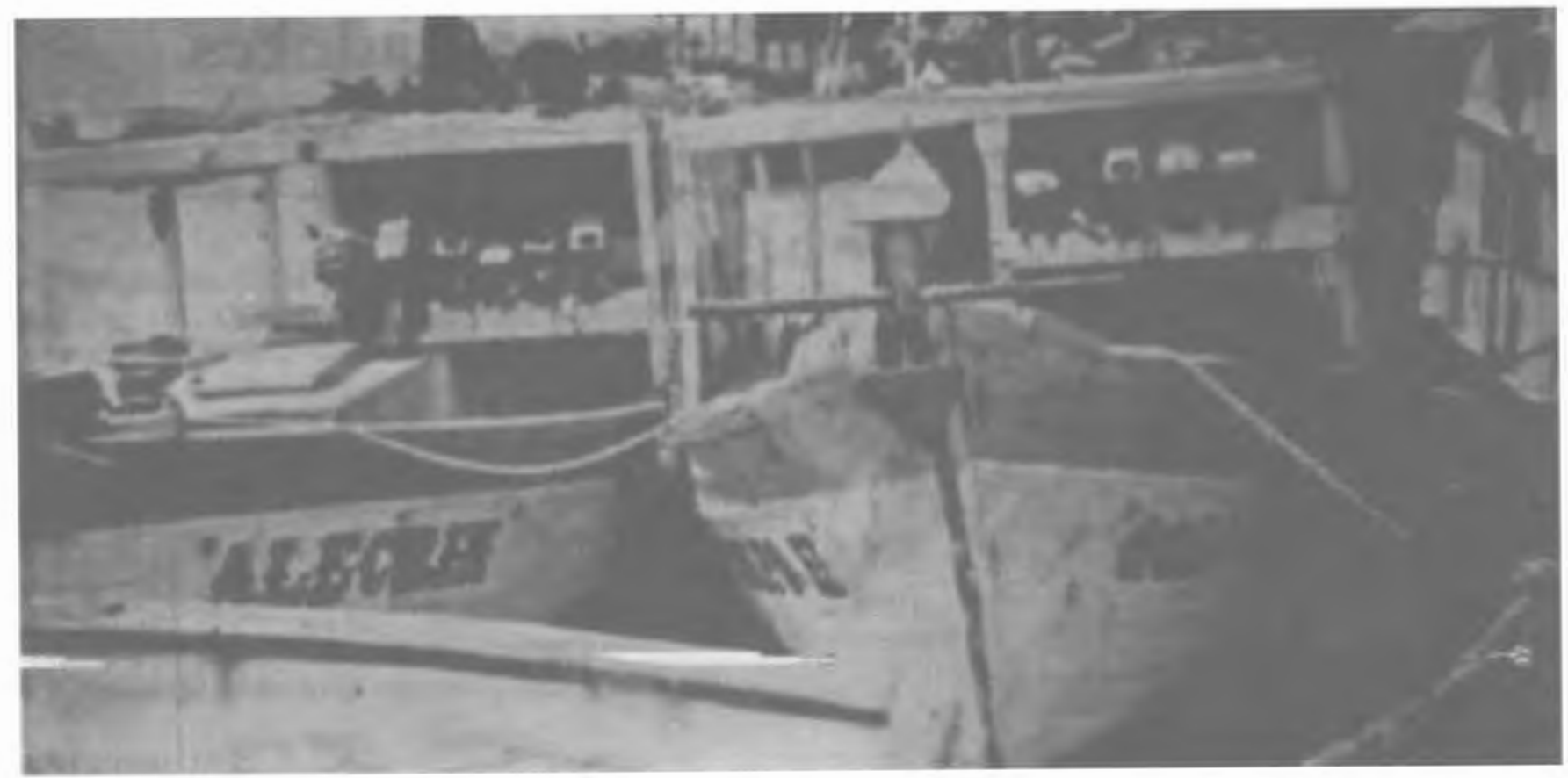

control aduanero.

En el Perú, este régimen está considerado en el D.S. Espeical № 13-PCM/93, publicado el 4/ 3/93, y elevado a Ley por la № 26200 publicada el 25.9.95. Los artículos pertinentes están considerados en la Ley General de Aduanas en la Sección I del CAPITULOSEXTO, con la siguiente definición:

Art. 7P.- "Entiéndase por Admisión Temporal el Ingreso de mercancias extranjeras con suspensión del pago de derechos e impuestos indicados en el Art. 2:' (se suspende o exonera, según corresponda, los derechos arancelarios, Impuesto Ceneral a las Ventas, Impuesto Selectivo al Consumo y demás impuestos que graven la importación de ciertas mercancias destinadas a procesos de elaboración o transformación) destinadas a ser exportadas, por si mismas o a través de terceros, luego de haber sufrido una transformación o elaboración en un plazo determinado".

En Centro América, dicho régimen estaba considerado en el Código Uniforme Centro Americano CAUCA, en el Art. 26 que autorizaba la importación temporal de mercancías, para exhibirlas, repararlas, para usos cien- tíficos o para cualquier otro fin.

El Art. 27, se refería al requisito de que sean claramente identificables.

El Art. 28, al plazo de tres meses prorrogable por igual periodo y las formas de caución o fianza.

Sin embargo algunos países del Mercado Común Centro Americano han adoptado en sus legislaciones algunos de los Regímenes de Perfeccionamiento Activo, incluso con denominaciones propias como el de"MAQUILA", con el fin de promocionar su industrialización y sus exportaciones así como el de dar ocupación a la mano de obra no muy especializada.

III. REPOSICION DE MERCANCIAS EN FRANQUICIA.- El Convenio de Kyoto, lo denomina "Régimen de Reaprovisionamiento en Franquicia" o Régimen exoneratorio. Definiéndolo como Régimen aduanero que permite la importación, libre de derechos e impuestos a la importación, de mer- cancías equivalentes (es decir, idénticas por su especie, calidad y sus características técnicas) a aquellas que estando en libre circulación (nacionales, nacionalizadas, manufacturadas) fueron utilizadas para obtener productos previamente exportados a título definitivo.

En el Perú, este régimen, tambien está considerado en el D.S. N ${ }^{2} 13-\mathrm{PCM} / 93$, publicado el $4 / 3 / 93$ y dado fuerza por Ley $N^{2}$ 26200, pub. el 25.9.93.

Definición.(Art. 18).-"Entiéndase por Reposición de Mercancías en Franquicia, al régimen por el cual se importa, con exoneración automática de los derechos arancelarios, Impuesto General a las Ventas, Impuesto Selectivo al Consumo, y demás impuestos que graven a la importación de mercancías equivalentes a las que habiendo sido nacionalizadas han sido transformadas, elaboradas o materialmente incorporadas en productos exportados definitivamente.

Se considera que las mercan- 
cíasson equivalentes, cuando son de la misma especie o similares en calidad y características técnicas, La exoneración, será otorgada sobre la misma cantidad de mercancías que fueron materialmente incorporadas a los productos exportados".

\section{IV.- DEPOSITOS DE} ADUANA.

Según lo define el Convenio de Kyoto: "Régimen aduanero por el cual, las mercancías importadas se almacenan bajo el control de la Aduana, en un lugar designado a este efecto, sin el pago de los derechos e impuestos a la importación". Existen dos categorías de depósitos, Depósitos de Aduana Públicos y Depósitos de Aduana particulares.

Este régimen aduanero, no debe confundirse con el que no es tal o sea con el "depósito temporal" o almacenes temporales o los llamados puerto secos o "Terminales de Almacenamiento" (locales cerrados y emplazamientos, acotados o no, aprobados por la aduana, donde se almacenan las mercancías por períodos muy cortos en espera de su despacho o pedido a algún régimen aduanero como el de Depósito).

Tampoco debe confundirse con el almacenamiento de las mercancías en "Puertos o Zonas Francas"; ni con el proceso de elaboración o de transformación de mercancías, bajo el control de la aduana con suspensión de los derechos e impuestos a la importación, en lugares aprobados por ella "Depósitos para Perfeccionamiento Activo".

En consecuencia, los Depósitos de Aduanas, son locales cerrados y aceptados por la aduana, donde las mercancías pueden ser almacenadas bajo el control aduanero por un período determinado, sin pago previo de los derechos e impuestos a la importación, los que sí según las condiciones del Depósito, en algunos países deben ser garantizados con una CAUCION $O$ FIANZA.

Se acepta que a estas mercancías, durante su permanencia en el Depósito se les de ciertos procedimientos como los de (distribución, acondicionamiento,cambio o reparación de embalajes, mezcla, etc.) que puedan facilitar su despacho a algunos de los regímenes que puedan acogerse.

En el Perú; el régimen de Depósitos de Aduana está considerado en los artículos Nos. 120 al 127, de la Ley General de Aduanas y en su Reglamento, además está contenido en el reglamento específico denominado "Reglamento de Almacenes Aduaneros" aprobado por D.S. No 08-95EF del 31.01.95, publicado el 5.2.95.

La Ley General de Aduanas en el Art. No 120 lo define como "Régimen aduanero con arreglo al cual las mercancías que llegan al territorio aduanero se almacenan bajo el control de la aduana en un lugar designado para este efecto sin el pago de los derechos e impuestos de importación".

Ampliada con el Art. 127 , al señalar el régimen a que se pueden acoger las mercancías allí depositadas; El plazo que se concede es de un año (Art. 125).

En Centro America, el CAUCA, en su Art. 117 , lo denominaba "ALMACENES GENE-

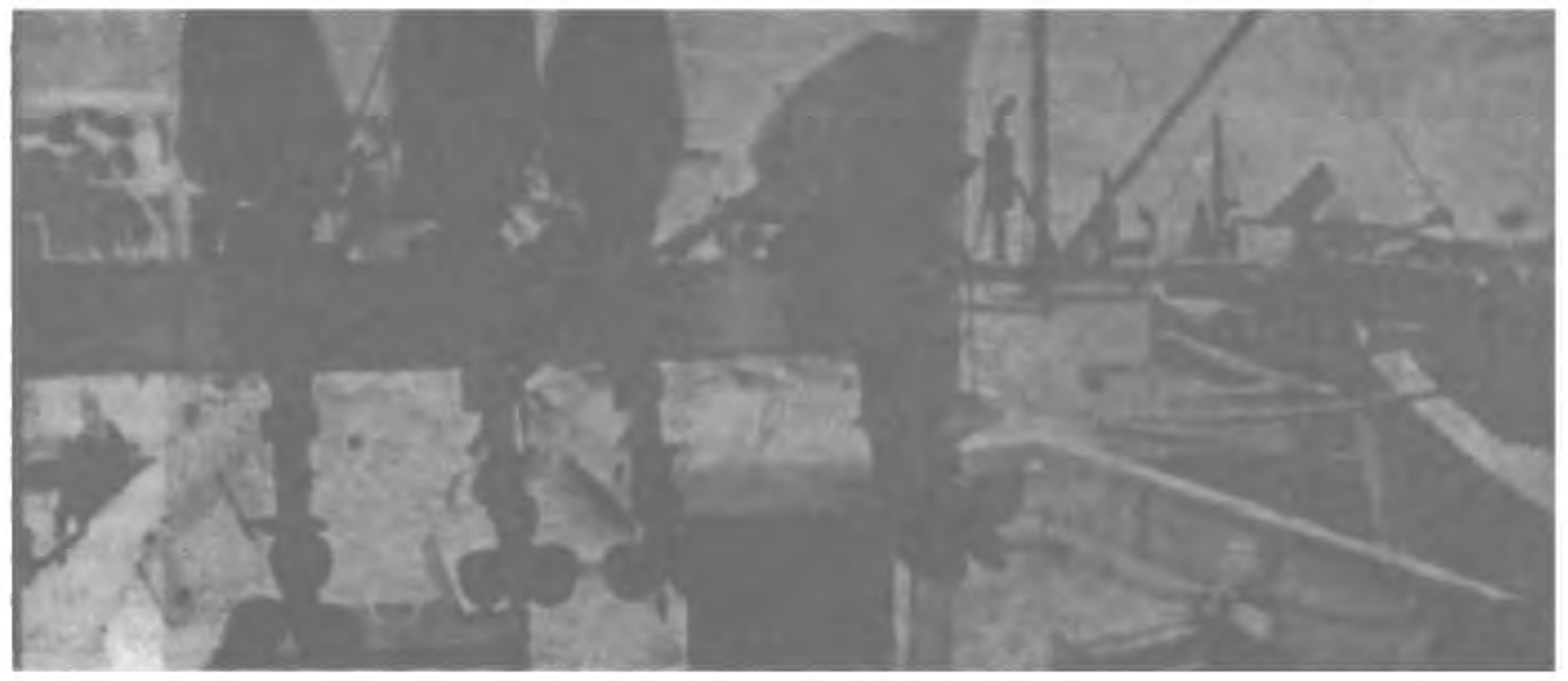


cías son equivalentes, cuando son de la misma especie o similares en calidad y características técnicas, La exoneración, será otorgada sobre la misma cantidad de mercancías que fueron materialmente incorporadas a los productos exportados".

\section{IV.- DEPOSITOS DE ADUANA.}

Según lo define el Convenio de Kyoto: "Régimen aduanero por el cual, las mercancías importadas se almacenan bajo el control de la Aduana, en un lugar designado a este efecto, sin el pago de los derechos e impuestos a la importación". Existen dos categorías de depósitos, Depósitos de Aduana Públicos y Depósitos de Aduana particulares.

Este régimen aduanero, no debe confundirse con el que no es tal o sea con el "depósito temporal" o almacenes temporales o los llamados puerto secos o "Terminales de Almacenamiento" (locales cerrados y emplazamientos, acotados o no, aprobados por la aduana, donde se almacenan las mercancías por períodos muy cortos en espera de su despacho o pedido a algún régimen aduanero como el de Depósito).

Tampoco debe confundirse con el almacenamiento de las mercancías en "Puertos o Zonas Francas"; ni con el proceso de elaboración o de transformación de mercancías, bajo el control de la aduana con suspensión de los derechos e impuestos a la importación, en lugares aprobados por ella "Depósitos para Perfeccionamiento Activo".

En consecuencia, los Depósitos de Aduanas, son locales cerrados y aceptados por la aduana,dondelas mercancías pueden ser almacenadas bajo el control aduanero por un período determinado, sin pago previo de los derechos e impuestos a la importación, los que sí según las condiciones del Depósito, en algunos países deben ser garantizados con una CAUCION $O$ FIANZA.

Se acepta que a estas mercancías, durante su permanencia en el Depósito se les de ciertos procedimientos como los de (distribución, acondicionamiento, cambio o reparación de embalajes, mezcla, etc.) que puedan facilitar su despacho a algunos de los regímenes que puedan acogerse.

En el Perú; el régimen de Depósitos de Aduana está considerado en los artículos Nos. 120 al 127, de la Ley General de Aduanas y en su Reglamento, además está contenido en el reglamento específico denominado "Reglamento de Almacenes Aduaneros" aprobado por D.S. No 08-95EF del 31.01.95, publicado el 5.2.95.

La Ley General de Aduanas en el Art. № 120 lo define como "Régimen aduanero con arreglo al cual las mercancías que llegan al territorio aduanero se almacenan bajo el control de la aduana en un lugar designado para este efecto sin el pago de los derechos e impuestos de importación".

Ampliada con el Art. $127^{2}$, al señalar el régimen a que se pueden acoger las mercancías allí depositadas; El plazo que se concede es de un año (Art. 125).

En Centro America, el CAUCA, en su Art. 1172, lo denominaba "ALMACENES GENE-

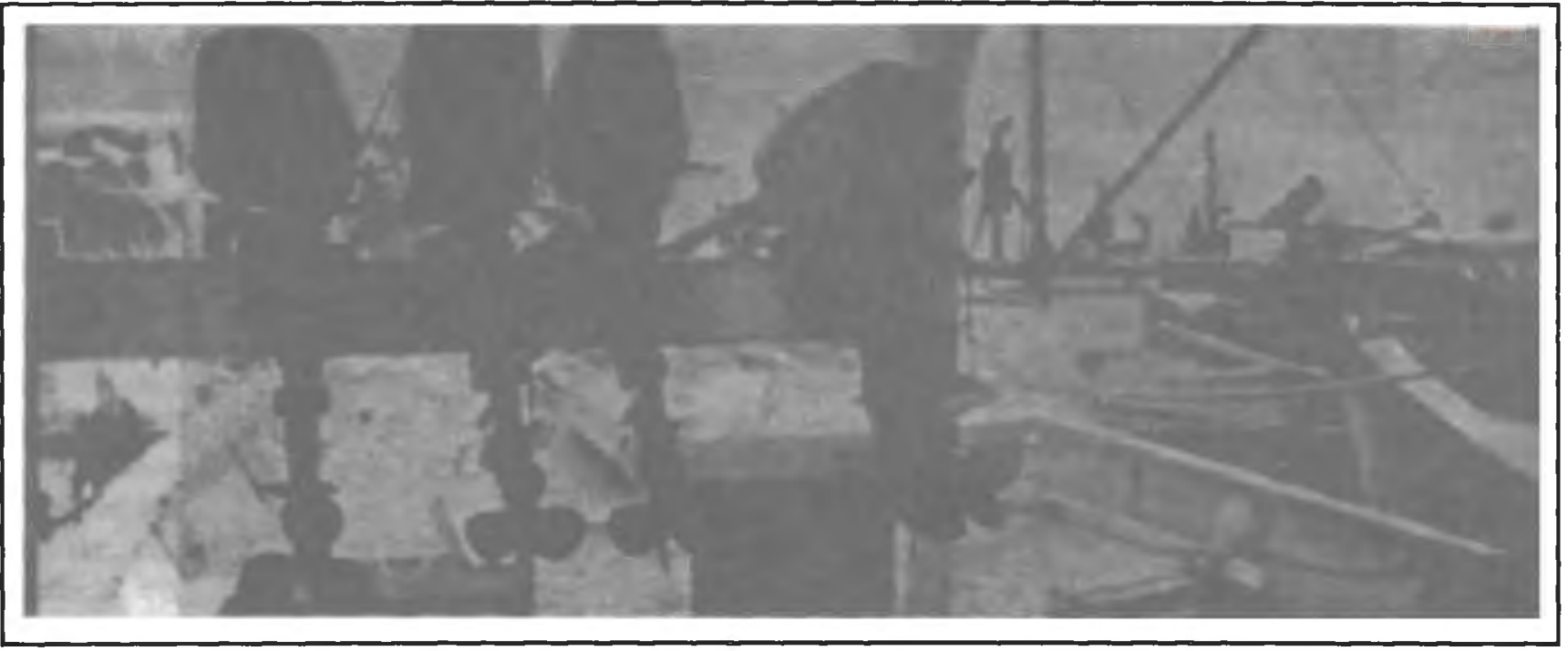




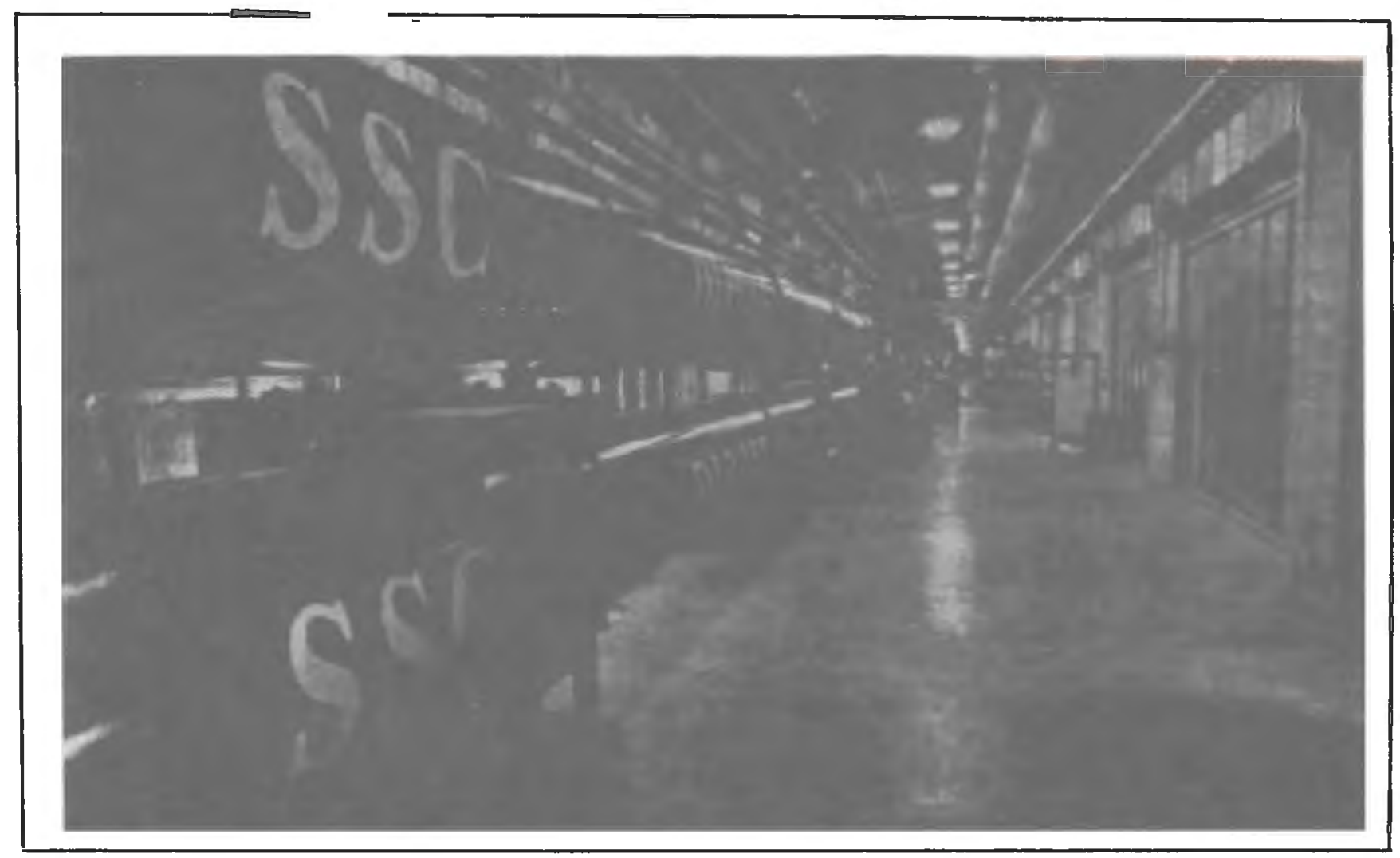

RALES DE DEPOSITO", dentro del rubro de regímenes suspensivos del pago de derechos y el plazo de la permanencia de las mercancías era concedida hasta por un año, prorrogable, hasta por un lapso igual (Art. 121 del (CAUCA), también disponía el aforo previo al ingreso a dichos almacenes generales (Art. 122) y que las mercancías alli almacenadas no podían ser objeto de cambio o modificación, salvo las operaciones que incluso la Convención de Kyoto las acepta (Art. 123, CAUCA).

NOTA.- El Convenio de Kyoto al hacer referencia a la procedencia de las mercanctas que son objeto de este régimen, como "importadas", no se refiere a las que hayan llegado para ese caso específico, sino también a aquellas mercancias que estén bajo otros regímenes $u$ operaciones aduaneras, incluso las que estén en tránsito.

V. DEPOSITOS INDUSTRIALES.- Régimen muy pare- cido al de Admisión Temporal, usado en Francia, países europeos y algunos americanos, como medida de fomento industrial $y$ de estímulo a las exportaciones, en reemplazo de las llamadas"Zonas o Puertos Francos".- Este régimen permite tener en cada fábrica o en lugares cercanos a éstas, un depósito de materias primas bajo el régimen suspensivo del pago de derechos e impuestos aduaneros.

VI. DRAWBACK (o reembolso).- Según el Convenio de Kyoto lo Define, como un "régimen aduanero que permite, en el momento de la exportación de las mercancías, obtener la restitución total o parcial de los derechos e impuestos de importación que hayan gravado, sea esas mercancías, o a los productos contenidos en las mercancías exportadas o las consumidas durante su producción".
En Drawback, relativo a las mercancías consumidas en el curso de la producción de las mercancias exportadas NO se extiende normalmente a los elementos que tienen un rol auxiliar en la fabricación, tales como los lubricantes los combustibles y el uso de las maquinarias y sus repuestos.

Para otorgar el Drawback o reembolso, las autoridades aduaneras tienen que solicitar ciertos requisitos e informaciones relativas:

a) al beneficiario;

b) al despacho inicial a consumo de las mercancías (por ejemplo, la fecha y el número de referencia de la Declaración de mercancías para despacho a consumo);

c) a los derechos e impuestos de importación que se hayan pagado;

d) a la naturaleza o a la desig- 
nación arancelaria de las mercancías y su cantidad;

e) a la utilización, elaboración o transformación a que se hayan sometido las mercancías, y cuadro insumo-producto;

f) a las condiciones de exportación.

En la legislación aduanera del Perú, este régimen aduanero está contenido en los artículos del № 159 al 161 de la Ley General de Aduanas.

Definición.- (Art. 159).- "Régimen aduanero que permite en el momento de la exportación de mercancías obtener la restitución total o parcial de los derechos e impuestos que hayan gravado la importación de dichas mercancías o la de los productos contenidos en las mercancías exportadas oconsumidas durante su producción".
NOTA.- Esta práctica o régimen, ha sido muy usado en Latino América, en décadas pasadas, por cuanto en muchas legislaciones aún no se contemplaba el de "Admisión Temporal para Perfeccionamietno Activo" niel de "Reposición en Franquicia" el que al haberse puesto en vigencia hizo que el "Drawback", casi cayera en desuso por ser éste último un régimen DEVOLUTIVO, lo que significa que el exportador ya pagó los derechos e impuestos intermedios, lo cual no sucede en el de Admisión Temporal, dónde solo se garantizan dichos derechos e impuestos, y que de acogerse al Drawback, significa "inversión de dinero" en estos pagos, aesperade su"devolucion" cuando se exportare el producto compensador, recurso que en nuestros países en desarrollo es caro y puede significar descapitalización a la empresa o al exportador.

Dicho régimen aduanero, se puede seguir usando pero creo que solamente en el caso de "exportadores" casuales, es decir, aquellos que siendo productores para consumo nacional, se les presente alguin pedido del extranjero y se les presente la oportunidad de exportar sus productos compensadores 0 compensatorios, como los define el Con- venio de Kyoto.

OBSERVACION.-Existeademás una diferencia entre el régimen del "Drawback" y el de Reposición en Franquicia", pues, mientras en el primero, las Aduanas, devuelven las sumas abonadas por derechos e impuestos a la importación de las materias primas e insumos utilizados, en el segundo, no se dá tal figura, ya que, se permite el libre ingreso por las cantidades de aquellas materias utilizadas en el "producto compensador" exportado, es decir, que en muchas ocasiones, con el monto reembolsado, ya no se podrá traer la misma cantidad de mercancía por que los precios internacionalmente varían, lo cual no sucede con la "reposición de las mercancías en franquicia". El primero es un régimen devolutivo, el segundo es régimen liberatorio.

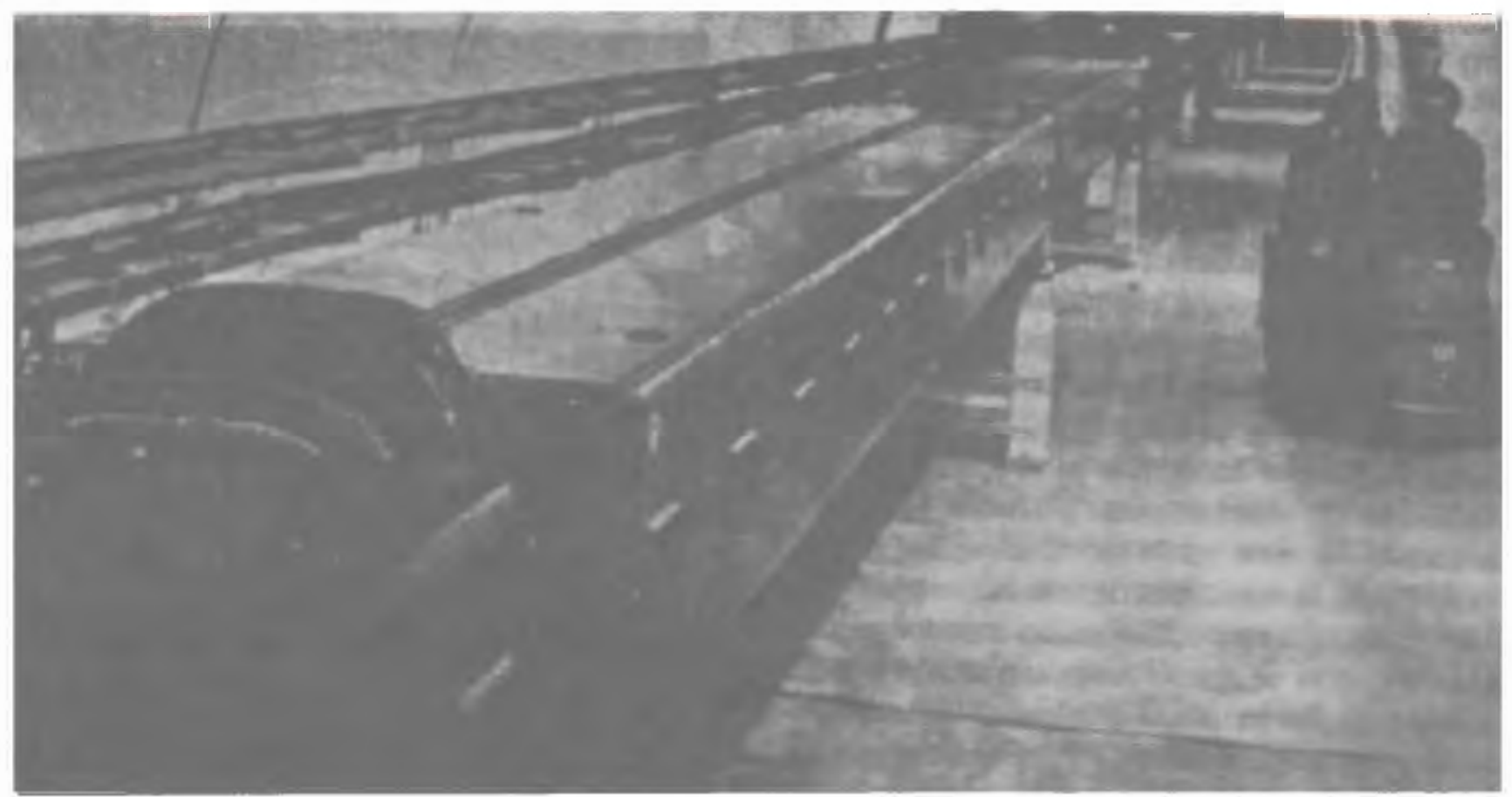

